\title{
LATIHAN ZIG-ZAG TERHADAP KELINCAHAN MENGGIRING BOLA PADA ATLET SEPAK BOLA
}

\author{
Muhammad Ihsan Shabih ${ }^{1}$, lyakrus², Destriani ${ }^{3}$ \\ 1,2,3 Program Studi Pendidikan Jasmani dan Kesehatan, Fakultas Keguruan dan IImu Pendidikan, \\ Universitas Sriwijaya \\ E-mail: ihsanshabih12@gmail.com¹, iyakrusanas@yahoo.com², destriani@fkip.unsri.ac.id ${ }^{3}$ \\ DOI: https://doi.org/10.36526/kejaora.v6i1.1289
}

\begin{abstract}
ABSTRAK
Penelitian ini bertujuan untuk mengetahui pengaruh latihan zig-zag terhadap kelincahan menggiring bola (dribbling) pada atlet sepak bola SSB Ogan llir United. Metode yang digunakan dalam penelitian ini adalah eksperimen semu (quasi experimen) dengan rancangan pretest dan posttest one group. Populasi penelitian ini adalah atlet SSB Ogan llir United yang berjumlah 30 orang. Sampel dalam penelitiaan ini berjumlah 30 orang. Instrumen dalam penelitian ini adalah tes dribbling zig-zag. Data diambil dari tes awal (pretest) dan tes akhir (posttest). Perlakuan dalam penelitian ini berupa latihan zig-zag diberikan latihan selama 5 minggu dengan frekuensi latihan 4 kali seminggu. Berdasarkan hasil penelitian dan analisis data statistik uji t dengan taraf signifikan $a=0,05$ didapat thitung $(30,5)$ sedangkan tabel $(1,70)$, maka thitung $>t_{\text {tabel }}$ sehingga $\mathrm{H}_{1}$ diterima dan $\mathrm{H}_{0}$ ditolak. Dengan demikian $\mathrm{H}_{1}$ dapat diajukan dan dapat diterima, bahwa latihan zig-zag berpengaruh terhadap kelincahan menggiring bola (dribbling) pada atlet sepak bola SSB Ogan llir United. Implikasi dari penelitian ini bahwa latihan zig-zag dapat digunakan sebagai salah satu jenis latihan untuk meningkatkan kelincahan menggiring bola (dribbling). Berdasarkan hasil penelitian ini bahwa latihan zig-zag memberikan pengaruh yang signifikan terhadap kelincahan menggiring bola (dribbling) pada atlet sepak bola SSB Ogan llir United.
\end{abstract}

Kata Kunci: Sepak Bola, Latihan Zig-Zag, Menggiring Bola (Dribbling), Kelincahan

\section{PENDAHULUAN}

Olahraga sepak bola merupakan olahraga yang begitu banyak disukai, digemari oleh siapapun baik tua, muda laki laki bahkan perempuan, permainan sepak bola seperti halnya semua kegiatan hidup manusia yang membentuk sikap jujur terhadap diri sendiri, sportivitas, fair play, bertanggung jawab dan memberanikan diri untuk mengambil keputusan (Pratama, 2017). Menurut Josep A (2012) Sepak bola adalah titik temu antara orang-orang dari berbagai latar belakang dan keturunan, yang menjadi jembatan penghubung semua tingkatan politik, ekonomi, budaya dan agama. Pratama (2017) juga mengemukakan bahwa sepakbola merupakan olahraga yang begitu indah penuh dengan kedamaian jika seseorang menikmati suatu pertandingan baik tingkat regional bahkan internasional yang memberikan kontribusi secara tidak langsung tanpa kita sadari bersama.

Udam (2017) mengemukakan bahwa teknik dalam permainan sepak bola meliputi 2 macam teknik yaitu: teknik dengan bola dan tanpa bola. Dalam permainan sepak bola terdapat beberapa teknik dasar yang harus dikuasai, diantaranya menendang bola, menghentikan bola, mengontrol bola, gerak tipu, tackling, lemparan kedalam dan teknik menjaga gawang (Udam, 2017). Beberapa keterampilan dasar yang dibutuhkan pemain sepak bola adalah menyundul (heading), menggiring (dribbling), menghentikan (stopping), dan menembak (shooting) (Daryanto \& Hidayat, 2015). Menurut Sukatamsi (dalam Efendi et al., 2018) mengemukakan bahwa teknik menggiring dibagi tiga macam yaitu: 1) Teknik menggiring dengan kura-kura bagian dalam, 2) Teknik menggiring dengan punggung kaki dan, 3) 
Jurnal Kejaora: Jurnal Kesehatan Jasmani dan Olah Raga

ISSN: 2541-5042 (Online)

ISSN: 2503-2976 (Print)

Volume 6 Nomor 1, Edisi April 2021

Teknik menggiring dengan kura-kura kaki bagian luar". Selain itu kelincahan menggiring sangat dibutuhkan untuk menunjang teknik tersebut. Untuk mencapai prestasi dalam kelincahan terhadap hasil menggiring harus didukung oleh kondisi fisik yang baik, penguasaan teknik dan psikologis (Efendi et al., 2018).

Kemampuan teknik dasar dalam permainan sepak bola juga harus didukung dengan kondisi fisik yang prima. Kondisi fisik merupakan salah satu faktor penting yang harus dimiliki setiap pemain sepak bola dalam upaya pencapaian prestasi maksimal. Kondisi fisik yang prima diperlukan agar latihan yang dilakukan dapat terlaksana dengan baik, terprogram, dan berkesinambungan sehingga tujuan latihan dapat tercapai (Ramdhon et al., 2018). Menurut Sukadiyanto (dalam Ramdhon et al., 2018) menyatakan bahwa kondisi fisik terdiri dari kekuatan, kecepatan, kelincahan, kelentukan, keseimbangan, koordinasi, dan daya tahan yang merupakan satu kesatuan utuh yang perlu mendapat perhatian dalam peningkatan dan pemeliharaannya. Ini tiada lain karena kondisi fisik merupakan pondasi atau dasar untuk melakukan aktivitas fisik lainnya seperti pelaksanaan teknik dalam olahraga (Tirtayasa et al., 2020; Sumerta, 2021).

Menurut Muhdhor (2013) bahwa menggiring adalah salah satu keterampilan sepak bola yang paling penting yang anda butuhkan untuk dikuasai. Sederhananya, jika anda tidak tahu bagaimana lawan anda menggiring bola, anda tidak akan tahu bagaimana bermain sepak bola. Menggiring bola merupakan keterampilan dasar dalam sepak bola karena semua pemain harus dapat mengontrol bola sambil bergerak, berdiri atau bersiap mengoper atau menembak (Mielke, 2013). Sedangkan menurut Luxbacher (2016) dribbling adalah keterampilan menggiring bola yang digunakan dalam keadaan yang sesuai, akan mengacaukan pertahanan lawan dan dua teknik dribbling menggiring bola dengan rapat dalam ruang yang terbatas dan menggiring bola dengan cepat untuk memasuki ruang terbuka merupakan hal yang penting dalam permainan. Ketika pemain telah menguasai keterampilan menggiring bola secara efektif,

kontribusi pemain pada permainan akan sangat bagus karena menggiring bola mewakili keterampilan lainnya sebagai salah satu penunjang dalam permainan sepak bola.

Latihan adalah suatu proses yang dilakukan secara sistematis dan berulangulang dalam jangka waktu yang relatif lama, dengan beban latihan yang semakin bertambah, agar terjadi peningkatan terhadap rangsangan gerak secara menyeluruh terhadap tubuh (Rahardian et al., 2019). Sedangkan menurut Harsono (dalam lyakus, 2012). tujuan latihan serta sasaran utama latihan bertujuan membantu atlet memaksimalkan keterampilan dan prestasinya meliputi empat aspek yaitu fisik, teknis, taktis, dan spiritual. Ada 3 bentuk latihan untuk meningkatkan kelincahan, yaitu shuttle run (lari bolak-balik), zig-zag run (lari belak-belok), dan lari rintangan (Apriyadi, 2014).

Muhajir (dalam Satriaputra \& Widodo, 2019) berpendapat bahwa kelincahan adalah kemampuan seseorang untuk mengubah arah dengan cepat dan akurat tanpa kehilangan keseimbangan saat bergerak. Karena kelincahan adalah kombinasi dari banyak komponen kecepatan, kekuatan, keseimbangan, dan koordinasi gerakan maka banyak cabang olahraga yang membutuhkan kelincahan (Satriaputra \& Widodo, 2019). Menurut Widiastuti (2017) kelincahan adalah mengacu pada perubahan arah atau posisi tubuh secara cepat yang dilakukan bersama sama dengan gerakan lainnya dan kelincahan memiliki peran yang penting demi tercapainya kemampuan penampilan secara baik untuk memiliki, memelihara dan menjaga agar kemampuan agility tetap menjadi satu kesatuan dengan kemampuan fisik lainnya.

Menurut Siswanto (dalam Hamdani, 2015). zig-zag adalah gerakan lari berbelokbelok mengikuti lintasan lari zig-zag dapat digunakan untuk meningkatkan kelincahan, karena unsur gerak yang terkandung dalam latihan lari zig-zag merupakan komponen gerak kelincahan yaitu lari dengan mengubah arah dan posisi tubuh, kecepatan, keseimbangan yang juga merupakan komponen gerak kelincahan. Upaya yang dapat dilakukan untuk meningkatkan kemampuan teknik dasar dribbling yang baik, 
Jurnal Kejaora: Jurnal Kesehatan Jasmani dan Olah Raga

ISSN: 2541-5042 (Online)

ISSN: 2503-2976 (Print)

Volume 6 Nomor 1, Edisi April 2021

yaitu dengan latihan zig-zag adalah gerakan lari berkelok-kelok mengikuti lintasan (Siswantoyo, 2003). Sedangkan menurut Luxbacher (2016) zig-zag adalah berlari melintasi cone dengan cara menggiring dan keluar masuk cone hingga mencapai cone terakhir, kemudian memutar arah mundur dan menggiring bola kembali ke posisi awal, jaga bola agar tetap dalam kontrol bola yang rapat setiap saat dan selesaikan secepat mungkin.

Berdasarkan hasil pengamatan yang telah dilakukan di SSB Ogan llir United pada saat para atlet melakukan kegiatan latihan rutin masih banyak ditemui kekurangan, khususnya pada saat menggiring bola (dribbling). Terdapat sekitar $80 \%$ Atlet masih ditemui kekurangan saat menggiring bola. Inilah yang menjadi masalah utama yang dialami oleh para atlet. Dalam melakukan gerakan menggiring bola (dribbling), atlet tidak dapat menguasai gerak yang diharapkan terutama pada kelincahan saat menggiring bola. Melihat kondisi tersebut, maka peneliti mencoba memberikan solusi dari permasalahan di atas, peneliti menggunakan metode latihan zig-zag untuk meningkatkan kelincahan menggiring bola pada pemain tersebut. Tujuannya adalah untuk mengetahui pengaruh latihan zig-zag terhadap kelincahan menggiring bola (dribbling) pada atlet sepak bola SSB Ogan Ilir United.

Dari latar belakang di atas, maka perlu dilakukan penelitian yang berjudul pengaruh latihan zig-zag terhadap kelincahan menggiring bola (dribbling) pada atlet sepak bola SSB Ogan llir United.

\section{METODE}

Penelitian ini adalah quasy eksperiment dengan mengunakan rancangan/desain penelitian "pretest dan posttest one group". Langkah pertama yang dilakukan adalah pengukuran (pretest), kemudian dilakukan perlakuan dalam jangka waktu tertentu, yang selanjutnya diteruskan dengan pengukuran kembali (posttest) untuk melihat ada atau tidaknya perbedaan sebelum dan sesudah pemberian perlakuan.

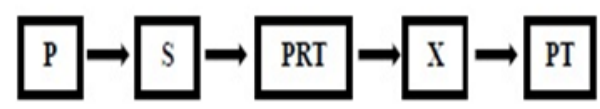

Gambar 1. Rancangan Penelitian Sumber: Sugiyono ( dalam Hartati, dkk., 2020)

\begin{tabular}{lll}
\multicolumn{2}{l}{ Keterangan: } \\
$\mathrm{P} \quad:$ & Populasi \\
$\mathrm{S}$ & $:$ & Sampel \\
$\mathrm{PRT} \quad:$ & Pre test (Tes Awal kelincahan \\
& menggiring bola (dribbling zig- \\
& zag)) test (Tes Akhir \\
$\mathrm{PT} \quad:$ & Post bola \\
& $\begin{array}{l}\text { kelincahan menggiring bola } \\
\text { (dribbling zig-zag)) }\end{array}$ \\
$\mathrm{X} \quad:$ & $\begin{array}{l}\text { Perlakuan } \\
\text { menggunakan metode latihan } \\
\text { lari zig-zag) }\end{array}$
\end{tabular}

Penelitian ini dilaksanakan dalam waktu 5 minggu. perlakuan dalam penelitian ini berupa latihan zig-zag dengan frekuensi latihan 4 kali seminggu. Semakin sering dan semakin banyak latihan maka peningkatan semakin cepat. Berikut program latihan yang diberikan:

Tabel 1. Program Latihan

\begin{tabular}{llll}
\hline Minggu & Materi & Volume & Intensitas \\
\hline 1 & Latihan & 3 set & $60 \%$ \\
& Zig-zag & & \\
\hline 2 & Latihan & 3 set & $65 \%$ \\
& Zig-zag & & \\
\hline 3 & Latihan & 3 set & $75 \%$ \\
& Zig-zag & & \\
\hline 4 & Latihan & 3 set & $80 \%$ \\
& Zig-zag & & \\
\hline 5 & Latihan & 3 set & $80 \%$ \\
& Zig-zag & & \\
& & & \\
\hline
\end{tabular}

Populasi dalam penelitian ini adalah atlet SSB Ogan llir United yang berjumlah 30 orang. Apabila subyek kurang dari 100 , lebih baik semua subyek dijadikan sampel, sehingga penelitiannya merupakan penelitian populasi. Sampel dalam penelitian ini adalah 30 orang atlet SSB Ogan Ilir United.

Instrumen tes yang digunakan adalah dribbling zig-zag. Dibawah ini adalah gambar 
Jurnal Kejaora: Jurnal Kesehatan Jasmani dan Olah Raga

ISSN: 2541-5042 (Online)

ISSN: 2503-2976 (Print)

Volume 6 Nomor 1, Edisi April 2021

instrumen tes dribbling zig-zag yang dikembangkan untuk mengukur kelincahan menggiring bola.

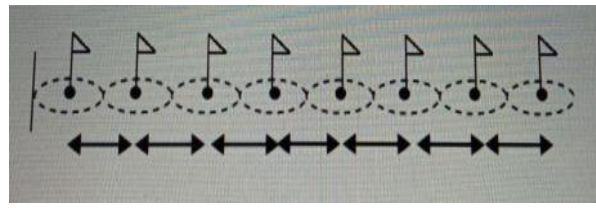

Gambar 2. Instrumen Dribbling Zig-zag

Sumber: Subagyo Irianto, dkk (2010: 3)

Teknik analisis yang digunakan peneliti dalam penelitian ini adalah uji T (test), langkah-langkahnya:

1. Uji normalitas data

2. Uji hipotesis

\section{HASIL DAN PEMBAHASAN}

Hasil penelitian dari 30 sampel yang diambil di SSB Ogan llir United, dari data pretest diperoleh data waktu tercepat 12,54 detik, data waktu terlambat 15,96 detik, mean 14,19, simpangan baku 0,82 dan kemiringan kurva sebesar 0,90 . Data posttest diperoleh data waktu tercepat 11,06 detik, data waktu terlambat 13,55 detik, mean 12,34, simpangan baku 0,6 dan kemiringan kurva 0,53 untuk lebih jelasnya bisa dilihat sebagai berikut:

Tabel 2. Distribusi Data Instrumen Tes Menggiring Bola (Pretest)

\begin{tabular}{lll}
\hline No. & Keterangan & Hasil \\
\hline 1. & Sampel (N) & 30 \\
\hline 2. & Waktu Tercepat & 12,54 \\
\hline 3. & Waktu Terlambat & 15,96 \\
\hline 4. & Rentang & 3,42 \\
\hline 5. & Banyak Kelas Interval & 6 \\
\hline 6. & Panjang Kelas & 0,57 \\
\hline 7. & Mean & 14,19 \\
\hline 8. & Modus & 13,45 \\
\hline 9. & Simpangan Baku & 0,82 \\
\hline 10. & Kemiringan Kurva & 0,90 \\
\hline
\end{tabular}

Berdasarkan tabel 1. dapat diketahui bahwa data waktu tercepat 12,54 , data waktu terlambat 15,96 , rentangnya sebesar 3,42 , rata-rata yang didapat dari pretest yaitu 14,19 , modus sebesar 13,45 , simpangan baku sebesar 0,82 , serta kemiringan kurva yang didapatkan dari hasil pretest yaitu 0,90.

Tabel 3. Distribusi Data Instrumen Tes Menggiring Bola (Pretest)

\begin{tabular}{lll}
\hline No. & Keterangan & Hasil \\
\hline 1. & Sampel (N) & 30 \\
\hline 2. & Waktu Tercepat & 11,06 \\
\hline 3. & Waktu Terlambat & 13,55 \\
\hline 4. & Rentang & 2,49 \\
\hline 5. & Banyak Kelas Interval & 6 \\
\hline 6. & Panjang Kelas & 0,41 \\
\hline 7. & Mean & 12,34 \\
\hline 8. & Modus & 12,02 \\
\hline 9. & Simpangan Baku & 0,6 \\
\hline 10. & Kemiringan Kurva & 0,53 \\
\hline & &
\end{tabular}

Berdasarkan tabel 2. dapat diketahui bahwa data waktu tercepat 11,06 , data waktu terlambat 13,55 , rentangnya sebesar 2,49 , rata-rata yang didapat dari posttest yaitu 12,34 , modus sebesar 12,02, simpangan baku sebesar 0,6 , serta kemiringan kurva yang didapatkan dari hasil posttest yaitu 0,53 .

Hasil tes awal (pretest) diketahui bahwa data waktu tercepat 12,54 dan data waktu terlambat 15,96 dengan rata-rata 14,19. Setelah diberikan perlakuan berupa latihan interval selama 5 minggu dengan frekuensi latihan 4 kali seminggu ternyata terdapat peningkatan rata-rata perbedaan tes awal (pretest) dan tes akhir (posttest) data waktu tercepat 11,06 dan data waktu terlambat 13,55 dengan rata-rata 12,34. Berikut tabel perbandingan antara pretest dan posttest kelompok eksperimen:

Tabel 4. Daftar Perbandingan Hasil Pretest dan Posttest

\begin{tabular}{llll}
\hline Hasil & Waktu & Waktu & Mean \\
& Tercepat & Terlambat &
\end{tabular}

\begin{tabular}{lrrr}
\hline Pretest & 12,54 & 15,96 & 14,19 \\
\hline Posttest & 11,06 & 13,55 & 12,34 \\
\hline
\end{tabular}

Perbandingan hasil pretest dan posttest di atas dapat dilihat hasil perbandingannya dari pretest menggiring bola tercepat yaitu 12,54 detik dan hasil tes menggiring bola terlambat 15,96 detik. Data hasil posttest menggiring bola tercepat yaitu 11,06 detik dan hasil tes menggiring bola terlambat yaitu 13,55 detik dan didapatlah 
Jurnal Kejaora: Jurnal Kesehatan Jasmani dan Olah Raga

ISSN: 2541-5042 (Online)

ISSN: 2503-2976 (Print)

Volume 6 Nomor 1, Edisi April 2021

mean atau rata-rata dari pretest sebesar 14,19 dan posttest sebesar 12,34 sehingga perbedaan mean pretest dan posttest sebesar 1,85 .

Pengujian dalam normalitas data, rumus yang digunakan adalah uji kemiringan kurva atau $\mathrm{Km}$ person. Berdasarkan perhitungan di atas, diketahui bahwa nilai kemiringan kurva untuk data pretest kelompok eksperimen adalah $(0,90)$ kemudian nilai kemiringan kurva untuk data posttest kelompok eksperimen adalah $(0,53)$. Berdasarkan nilai-nilai tersebut, maka baik pada saat pretest maupun posttest data terdistribusi normal yaitu terletak antara $(-1)$ dan $(+1)$.

Tabel 5. Daftar Uji Hipotesis

\begin{tabular}{lllll}
\hline Hasil & Mean & $\sum d$ & $\sum x d$ & $\sum X^{2}$ \\
\hline Pretest & 14,19 & 55 & 0,1 & 3,2014 \\
Posttest & 12,34 & & & \\
\hline
\end{tabular}

Berdasarkan tabel uji hipotesis dapat diketahui hasil data pretest kelompok eksperimen dengan rata-rata 14,19 dan data posttest kelompok eksperimen dengan ratarata 12,34 dan diketahui juga $\sum d$ berjumlah 55 , $\sum x d$ berjumlah 0,1 dan $\Sigma X d^{2}$ berjumlah 3,2014 .

Data hasil perhitungan statistik "uji t" didapat hasil 30,5 sedangkan $T_{\text {tabel }}$ adalah 1,70 yang diperoleh dari tabel distribusi $T$ dengan $\mathrm{dk}(30-2)=28$ dan taraf kepercayaan $95 \%(\alpha=0,05)$,tercantum dalam tabel. Kriteria pengujian hipotesis terima $\mathrm{H}_{1}$ jika $T_{\text {hitung }}>T_{\text {tabel(1-a), }}$ dan tolak $\mathrm{H}_{0}$ jika $T_{\text {hitung }}<T_{\text {tabel(1- }}$ a), Karena thitung $(30,5)>t_{\text {tabel }}(1,70)$ maka terdapat perbedaan yang signifikan antara post-test dan pre-test, dengan demikian maka hipotesis $\mathrm{H}_{0}$ ditolak dan hipotesis $\mathrm{H}_{1}$ diterima. Pernyataan $\mathrm{H}_{1}$ yaitu "Terdapat pengaruh latihan zig-zag terhadap kelincahan menggiring bola (dribbling) pada atlet sepak bola SSB Ogan llir United".

Pembahasan

Berdasarkan kriteria penelitian bahwa diperlukan pembahasan untuk menyusun hasil penelitian yang akan dibahas tentang hasil data pretest dan posttest serta hasil data pengaruh latihan zig-zag terhadap kelincahan menggiring bola (dribbling) pada atlet sepak

bola SSB Ogan llir United dalam kriteria sebagai berikut: Penelitian ini dilakukan selama 5 minggu dengan frekuensi latihan 4 kali seminggu sesuai dengan pendapat Bompa dalam Apta Mylsidayu dan Febi kurniawan (2015:50) yang mengatakan bahwa: "peningkatan hasil latihan terjadi dalam waktu 2-6 minggu tetapi biasanya 4 minggu (1 bulan). Hal ini yang perlu diperhatikan adalah peningkatan dalam latihan apablia latihan dilakukan minimal 3 kali seminggu dan maksimal 12-14 kali dalam seminggu (sehari 2 sesi)". Semakin sering dan semakin banyak latihan maka peningkatan semakin cepat, akan tetapi harus memperhatikan prinsip-prinsip latihan agar tidak overtraining, untuk itu perkembangan komponen kondisi fisik yang terbaik juga membantu seorang atlet untuk mampu mengikuti latihan selanjutnya dalam usaha mencapai prestasi setinggi-tingginya.

Berdasarkan hasil data pretest kelompok eksperimen terdapat 30 atlet yang telah melakukan tes kelincahan menggiring bola dengan memperoleh waktu yang berbeda-beda. Hasil data pretest menunjukkan bahwa terdapat seorang atlet yang memperoleh data terbesar 15,96 (waktu terlambat) dan seorang atlet yang memperoleh data terkecil 12,54 (waktu tercepat). Nilai Mean diperoleh dari hasil menjumlahkan $\frac{\Sigma f i x i}{\Sigma f i}$ (jumlah frekuensi dikali nilai tengah : jumlah frekuensi) dengan hasil sebesar 14,19 , nilai modus diperoleh dari hasil menjumlahkan $\mathrm{b}+\mathrm{p}\left(\frac{b_{1}}{b_{1}+b_{2}}\right)(\mathrm{b}=$ Batas bawah kelas modal, yaitu interval dengan frekuensi terbanyak, $p=$ Panjang kelas, $b_{1}=$ Frekuensi kelas modus dikurangi frekuensi kelas interval dengan kelas yang lebih kecil, $b_{2}=$ Frekuensi kelas modus dikurangi frekuensi kelas interval dengan kelas yang lebih besar sesudah tanda kelas modus) dengan hasil data 13,45 , serta nilai standar deviasi diperoleh dari hasil menjumlahkan $\frac{n \sum f i x i^{2}-\left(\sum f i x i\right)^{2}}{n(n-1)} \quad$ yaitu $\quad 0,82, \quad$ dan kemiringan kurva diperoleh dengan cara memasukkan nilai hitung yang didapat (modus, rata-rata, dan standar deviasi) kedalam rumus $\frac{\bar{X}-M o}{S}$ dengan hasil sebesar 
Jurnal Kejaora: Jurnal Kesehatan Jasmani dan Olah Raga

ISSN: 2541-5042 (Online)

ISSN: 2503-2976 (Print)

Volume 6 Nomor 1, Edisi April 2021

0,90. Data hasil posttest diperoleh dengan cara yang sama seperti cara penghitungan hasil data pretest, dengan data terbesar 13,55 (waktu terlambat) dan data terkecil 11,06 (waktu tercepat) dengan mean 12,34, modus data 12,02 , serta standar deviasi yaitu 0,6 dengan kemiringan kurva 0,53 . Rata-rata dari pretest ke posttest naik 1,85. Berdasarkan nilai-nilai tersebut, maka baik pada saat pretest maupun posttest data berdistribusi normal, yaitu terletak antara (-1) dan $(+1)$.

Hasil penelitian di atas menunjukkan bahwa latihan zig-zag dapat digunakan untuk meningkatkan kelincahan menggiring bola pada atlet sepak bola SSB Ogan Ilir United. Hal ini dapat dilihat dari adanya peningkatan kelincahan antara pretest dan posttest setelah diberi perlakuan latihan zig-zag.

Berdasarkan uji hipotesis, data pretest kelompok eksperimen dengan rata-rata 14,19 dan data posttest kelompok eksperimen dengan rata-rata 12,34 . Diketahui juga $\sum \mathrm{d}$ berjumlah $55, \sum x d$ berjumlah 0,1 dan $\sum x d^{2}$ berjumlah 3,2014 .

Berdasarkan hasil perhitungan statistik "uji t" didapat hasil 30,5 sedangkan $T_{\text {tabel }}$ adalah 1,70 yang diperoleh dari tabel distribusi $T$ dengan $\mathrm{dk}(30-2)=28$ dan taraf kepercayaan $95 \%(\alpha=0,05)$, tercantum dalam tabel. Kriteria pengujian hipotesis terima $\mathrm{H}_{1}$ jika $T_{\text {hitung }}>T_{\text {tabel(1-a), dan tolak } \mathrm{H}_{0} \text { jika } T_{\text {hitung }}<}$ $T_{\text {tabel(1-a), }}$ Karena thitung $(30,5)>t_{\text {tabel }}(1,70)$ maka terdapat perbedaan yang signifikan antara post-test dan pre-test, dengan demikian maka hipotesis $\mathrm{H}_{0}$ ditolak dan hipotesis $\mathrm{H}_{1}$ diterima. Pernyataan $\mathrm{H}_{1}$ yaitu "Terdapat pengaruh latihan zig-zag terhadap kelincahan menggiring bola (dribbling) pada atlet sepak bola SSB Ogan llir United".

\section{KESIMPULAN}

Berdasarkan hasil penelitian dan analisis data, menunjukkan bahwa latihan zig-zag memberikan pengaruh yang signifikan terhadap kelincahan menggiring bola. Implikasi dari penelitian ini bahwa latihan zigzag dapat digunakan sebagai salah satu jenis latihan untuk meningkatkan kelincahan menggiring bola (dribbling). Dengan demikian dapat disimpulkan bahwa latihan zig-zag memberikan pengaruh yang signifikan

terhadap kelincahan menggiring bola (dribbling) pada atlet sepak bola SSB Ogan Ilir United.

\section{UCAPAN TERIMA KASIH}

Dalam proses pembuatan artikel ini terdapat banyak sekali bantuan dari berbagai pihak. Oleh karena itu, diucapkan terima kasih yang sebesar-besarnya dan setulustulusnya kepada yang terhormat:

1. Dr. Hartati, M.Kes., selaku Koordinator Program Studi Pendidikan Jasmani dan Kesehatan FKIP Universitas Sriwijaya.

2. Dr. lyakrus, M.Kes., selaku Pembimbing Akademik yang telah memberikan bimbingan, motivasi, saran, dan masukan dalam penyelesaian penelitian ini.

3. Destriani, M.Pd., selaku Pembimbing Jurnal yang telah memberikan bimbingan, motivasi, saran, dan masukan dalam penyelesaian penelitian ini.

4. Seluruh staff dosen dan pegawai Program Studi Pendidikan Jasmani dan Kesehatan yang telah memberikan pengetahuan dan membantu kelancaran penelitian ini.

5. Kedua orang tua dan keluarga besar yang telah memberikan dorongan secara moril dan materi sehingga penelitian ini dapat diselesaikan.

6. Presiden klub dan staff pelatih SSB Ogan Ilir United yang telah memberikan bantuan dalam penelitian ini.

7. Semua pihak yang tidak dapat peneli sebutkan satu persatu yang telah banyak memberikan bantuan dalam penelitian ini.

\section{DAFTAR PUSTAKA}

Anas, I. (2012). Penerapan Closed Skill dan Open Skill dalam Latihan Sepaktakraw di Penjas FKIP Universitas Sriwijaya. Jurnal IImu Olahraga Dan Kesehatan Altius, 1-6.

Arikunto, S. (2013). Prosedur Penelitian, Suatu Pendekatan Praktik. Jakarta: PT Rineka Cipta.

Apriyadi, I., Dwi Rosella, K., St FT, S., Santoso, T. B., \& Fis, S. (2014). Pengaruh Agility Ladder Exercise 
Jurnal Kejaora: Jurnal Kesehatan Jasmani dan Olah Raga

ISSN: 2541-5042 (Online)

ISSN: 2503-2976 (Print)

Volume 6 Nomor 1, Edisi April 2021

Dengan Metode Lateral Run Terhadap Peningkatan Kelincahan Lari Pada Atlet Sepakbola Usia 13 Tahun DiSekolah Sepak Bola Jaten (Doctoral dissertation, Universitas Muhammadiyah Surakarta).

Daryanto, Z. P., \& Hidayat, K. (2015). Pengaruh latihan kelincahan terhadap kemampuan menggiring bola. Jurnal Pendidikan Olahraga, 4(12), 201-212. https://journal.ikippgriptk.ac.id/index.p hp/olahraga/article/view/87/85

Efendi, A. R., Pahliwandari, R., \& Arifin, Z. (2018). Pengaruh latihan kelincahan terhadap kemampuan menggiring dalam permainan sepakbola mahasiswa UKM Sepakbola IKIP PGRI Pontianak. Jurnal Pendidikan Olahraga, 7(1), 1-10.

Hamdani. (2015). Strategi Belajar Mengajar. Jakarta: Rineka Cipta.

Hartati, H., Solahuddin, S., \& Irawan, A. (2020). Latihan Kelincahan Dan Keseimbangan Untuk Meningkatkan Hasil Dribble Sepak Bola. Altius: Jurnal Ilmu Olahraga Dan Kesehatan, 9(1), $\quad 38-46$. https://doi.org/10.36706/altius.v9i1.11 557

Irianto, S. (2010). Pengembangan Tes Kecakapan "David Lee" untuk Sekolah Sepak Bola (SSB) Kelompok Umur 1415 Tahun.

Irianto, S., dkk. (2010). Penyusunan Tes Keterampilan Bermain Sepakbola Bagi Siswa Sekolah Sepak Bola PUSPOR IKIP Yogyakarta. Yogyakarta: FIK UNY.

Luxbacher, J. A. (2016). Sepak Bola langkahlangkah menuju sukses. Jakarta:Kharisma Putra Utama Offset.

Mielke, D. (2009). Dasar-dasar Sepak bola. Bandung: Human kinetics.

Muhdhor, Z. A. (2013). Menjadi Pemain Sepakbola Profesional. Teknik, Strategi, Taktik Menyerang \& Bertahan. Jakarta: Kata Pena.

Pratama, R. R. (2017). Tingkat Keterampilan Tehnik Dasar Sepakbola Tim Lpi Mahasiswa Unsri Tahun 2012. Altius: Jurnal IImu Olahraga Dan Kesehatan, $6(2)$, 156-159. 
Jurnal Kejaora: Jurnal Kesehatan Jasmani dan Olah Raga

ISSN: 2541-5042 (Online)

ISSN: 2503-2976 (Print)

Volume 6 Nomor 1, Edisi April 2021

Widiastuti. (2017). Tes dan Pengukuran Olahraga. Jakarta: PT. Raja Grafindo Persada. 